\title{
Os efeitos de raccords na literatura
}

Noemi Araújo ${ }^{1}$

Resenha do livro Ó. RAMOS, Nuno. São Paulo: Iluminuras, 2009.

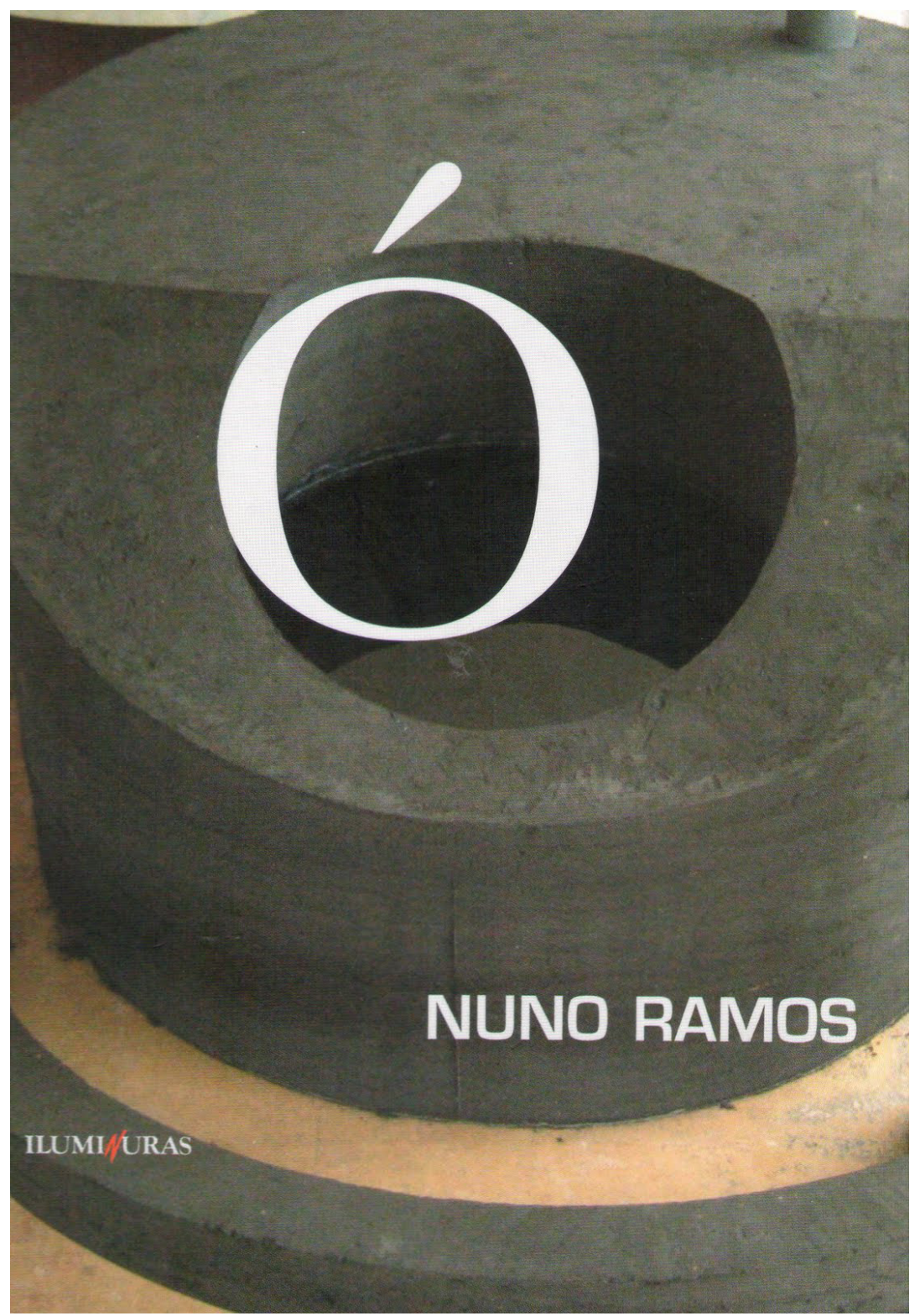


Ó, de Nuno Ramos, segundo José Antônio Pasta, existe ali onde ele não é. A artista gráfica Sandra Antunes o apresenta como o ponteiro do "relógio solar". A Portugal Telecom de Literatura o premiou na sua sétima edição por considerá-lo inclassificável. Esse título de uma letra só causa estranhamento; apesar de não ter citações, notas de rodapé e referências bibliográficas, seu autor faz uma concessão. Na última página, sem-número, há o texto "Observação", como se esta fosse uma página a mais do livro ou um anexo com nomes de autores e obras que o inspiraram na concepção dos capítulos 2, 3 e 5: "Tumba da família Brion", do arquiteto Carlos Scarpa; o romance Perturbação, de Thomas Bernhard; uma colagem de gravuras de Oswaldo Goeldi. Sem-prefácio, sem-introdução, o livro e seu autor são apresentados pelo projeto gráfico, assinado por Sandra Antunes, e pela orelha do livro, escrita pelo artista plástico José Pasta.

Na capa, a artista gráfica faz um enredo do título desse livro com outra obra do escritor, realizada no âmbito das artes plásticas: "O que são as horas?" (2005), feita de areia queimada e óleo queimado. Fundindo a vogal ó (com acento agudo) com a imagem do buraco dessa obra, a artista gráfica Sandra Antunes apresenta o autor pela sua particularidade de fazer a migração da palavra (e do número?) para o universo da imagem em suas realizações artísticas, desde o início dos anos 1990. Sua instalação em memória dos 111 mortos na chacina do Carandiru (1992) marcou essa fase.

Nuno Ramos é considerado pela crítica não só um artista que ultrapassa os limites do quadro, ajunta materiais que aparentemente não poderiam se ligar, mas que está sempre no limite entre as artes plásticas e a literatura, atravessadas pela linguagem cinematográfica. Sua ideia de "palavra como furo" foi materializada em sua segunda publicação, Balada (1995), com 900 páginas em branco perfuradas por uma bala (ao meio). Em sua fase de "perfurar" o livro com palavras, publicou Cujo (1993), O pão do corvo (2002) - enquadrado 
pela crítica "no limite" entre o conto, o poema e o ensaio - e Ensaio geral (2007). Formado em filosofia pela USP, certa vez declarou que seu laço social com essa área do conhecimento passa por Pascal e, com a literatura, pela produção de Antonio Candido.

O texto destinado à orelha funde-se, na verdade, ao texto da contracapa, permitindo ao leitor que entre no livro pelo avesso, podendo ainda ler de trás para frente, de fora pra dentro, em movimento contínuo. Pasta, que deveria apresentar a obra, salienta o seu caráter não convencional ou não comercial, comentando as possibilidades de reflexão que ele provoca.

Mas o "ó do borogodó" desse livro pode ser o inventário do corpo como linguagem. Ou seja, Ó pode ser um momento no "a, e, i, o, u" do humano. Ou ainda a narrativa de uma experiência deste ser com as coisas de seu corpo estruturado como linguagem, num tempo que o deteriora. Seu narrador indaga sobre a diferença entre o humano e o animal por sua capacidade de escolher perder tempo, ou não, pois "só os humanos perdem tempo", exatamente porque "dispõem também da possibilidade de ganhá-lo"; ou de nascer, viver e morrer em suas experiências, "cuspindo no tempo". Não por acaso, a imagem da capa mostra uma sombra dentro do buraco que é uma representação do ponteiro de um "relógio solar". A vogal "o" jogada na esteira do buraco e o acento agudo em cima produzem uma alegoria da intervenção do humano no "relógio" da natureza - vê-se um olho aberto ou um Ó?

Esse acento anunciado na capa pode ser associado ao modo pelo qual o autor faz um uso livre da pontuação e da acentuação. Sem intimidar-se, Nuno apropria-se da vogal maiúscula usando-a de seu jeito no meio da frase, independentemente de ela estar ou não posicionada também no início da oração ou após o ponto final. Outro dos exemplos de seu uso pessoal do texto é a construção de um parágrafo com mais de 70 palavras...

Ó é estruturado com 25 textos, distribuídos em 283 páginas, mais aquela sem número. Entre estes, encontram-se sete escritos curtos que o autor 
chamou de "Ó", escritos integralmente com letras em itálico, na maioria das vezes com apenas um ponto final. Aqui o itálico é um significante (qualquer) que perpassa todo o livro, pondo o "capítulo" em relação com seu grande "O". Assim, não necessariamente a passagem de um parágrafo para outro é mediada por pontos ou vírgulas, mas pelo próprio espaço e tempo do texto. Essa passagem, a princípio, é estranha, mas não impossibilita o bom ritmo de sua leitura. No espírito lacaniano do termo, essa obra deixa para seu leitor a tarefa de fazer sua nomeação singular. Poema, conto, romance? Não importa! Cada leitor é um. Cada leitura é uma.

O texto de número 1, "Manchas na pele", revela o objeto central da obra - uma conversa do homem com a própria estranheza de seu corpo enquanto linguagem. A dialética da linguagem do corpo, da vida e da morte, atravessada na obra, é explicitada no segundo texto, cujo título é "Túmulo". E também no último, "Espelho", por se tratar da representação da experiência humana diante de sua imagem refletida no espelho e pela simplicidade da pergunta que fecha o texto e o livro: "O que você acha disto?". Numa entrevista para a televisão, Deleuze (1996) disse que não é a quantidade de álcool que o alcoólatra consome durante o dia que importa, mas sim o seu último gole. Ora, é este que lhe possibilitará tomar o primeiro gole do dia seguinte. Outro dia. O recomeçar tudo de novo, os demais goles são repetições à espera do último.

A inscrição "São Paulo, 2002-2008", na última página, não passa de todo despercebida. Uma data qualquer, que pode representar aquela de nascimento e a da primeira morte simbólica da obra. Em 2009, com sua publicação, ela nasce novamente, no campo do outro.

Em Além do princípio do prazer (1920), no âmbito da discussão do conceito de repetição (no sentido da segunda morte como sendo a simbólica), Freud usa o exemplo de uma mulher que se casou três vezes, tendo os maridos adoecido após o matrimônio, e faz referência à representação do poema épico "Gerusalemme Liberata" (Torquato Tasso, 1581), em que Tancredi mata sua 
amada Clorinda por duas vezes. No poema, na ópera ou na pintura, esse mito é considerado o retrato poético mais comovente de um destino. Sua representação cinematográfica repercute em Sétimo selo (Ingmar Bergman, 1956). Uma série em que Ó pode ser incluído?

Nuno decidiu estruturar esse livro como uma linguagem cinematográfica ao fazer marcações ou pontuações com os sete "Ós". Ou será talvez como um raccord? Ou seja, uma relação entre dois planos na linguagem cinematográfica ligados em continuidade (ou não) de tempo e de espaço. O primeiro "Ó" é o texto de no 4 e é a quarta vogal. Já o sétimo "Ó" é o de no 24 (p. 269). Isto nos remete à ideia de sétima arte - o cinema. Nesta arte, para construir-se uma imagem, são necessários 24 quadros (fotogramas) por segundo. O texto de no 25 seria a imagem projetada invertida na tela, como num "Espelho"?

Na escolha de narrativa do autor, há algo do real da escrita: "Nosso corpo é quem de algum modo fala" (p. 26). A escrita não existe! Há uma letra, ou palavra, que dará conta da representação de uma imagem que funde corpo e linguagem? Para dizer dessa impossibilidade de significar, figurar, representar o corpo, Lacan escolheu a letra "a", em itálico que ele chamou de "objeto a"... 